\title{
Announcement
}

Neuropsychobiology

Neuropsychobiology 2000;41:166-170

\section{CINP Congress}

Collegium Internationale Neuro-Psychopharmacologicum

'At the Interface between Psychiatry and Neurology'

Brussels, July 9-13, 2000

Scientific secretariat:

Hôpital Erasme, U.L.B.

Department of Psychiatry

Dr. D. Souery

Route de Lennik, 808

B-1070 Brussels (Belgium)

Tel + 3225554409, Fax + 3225554515

E-Mailcinp2000@ulb.ac.be

http://www.cinp2000.be

Organisation

ICEO

Congress Coordinator

Valérie Wouters

Avenue de l'Atlantique, 122

B-1150 Brussels (Belgium)

Tel. +32 27795959, Fax +3227795960

E-Mailinfo@iceo.be

http://www.iceo.be

\section{KARGER}

(c) 2000 S. Karger AG, Basel

Fax +41613061234

E-Mail karger@karger.ch

www. karger.com
Accessible online at:

www. karger.com/journals/nps 